\title{
Corpo Transpessoal: O contributo espiritual da Performance para a construção pictórica.
}

\author{
Sónia Carvalho
}

Faculdade de Belas-Artes da Universidade de Lisboa

ID+ Instituto de Investigação em Design Media e Cultura, Portugal

CIEBA, Centro de investigação e de Estudos em Belas-Artes, Portugal

Paulo Bernardino Bastos

Universidade de Aveiro | DeCA

ID+ Instituto de Investigação em Design Media e Cultura, Portugal

Rui Alexandre Rosa Grincho Serra

Faculdade de Belas-Artes da Universidade de Lisboa

CIEBA, Centro de investigação e de Estudos em Belas-Artes, Portugal

\begin{abstract}
After my practical-theoretical project TRANSPERSONAL BODY - which seeks to question the meaning of the representing action of the transpersonal and numinous body in the context of the contemporary image (whether pictures and moving images). The practice is based on painting versus cinema as an expanded field, resulting from performative contexts, and on the relationship that is proposed in the experience of the poetry of the other.

The paradigm underlying the pictorial processes as an extension of the performative will be considered, in the context of the practice of ritual performance, from an anthropological perspective of the body, the study of symbols and archetypes and the verification of psychology transpersonal. For this, the video will be considered not only a documentary medium of the performative records (Practice-led Research), as well as an independent artistic object - it results as another element in the construction of the narrative of the actions between the body and the image - the performative body ritualized as an video object.

To the performativity intrinsic to the project, participative observation is proposed as a study method, using processes of personal and cognitive transformation in order to enhance expanded states of consciousness; as a contribution to the process of conquering the internal image (vision) and, in a concern with the transpersonal dimension, as well as for the visual (re) enchantment, relating art and spirituality.
\end{abstract}

Keywords: Performance, Painting, Body, Spirituality, Female.

\section{Introdução}

$\mathrm{Na}$ atual Era da Informação, o paradigma muda da produção do objeto como sustento económico, para focar toda a atenção na produção e manipulação da imagem. As imagens entram pelas casas a uma velocidade atroz e são consumidas confortavelmente como informações, até então proporcionadas pelos jornais, poupando desta forma o cansaço da leitura.
Com o Big Data, a quantidade de dados produzidos e a virtualização destes requere a sua especialização, bem como, a necessidade de catalogar, documentar e dar sentido aos conteúdos. A realidade passa a ser imagem, a existir enquanto tal, tornando-se objeto incorpóreo de informação manipulada.

Desta forma, o excesso de informação exige encontrar soluções para o arquivo, nomeadamente a capacidade de armazenamento, bem como a gestão do suporte mais adequado à função pretendida. É neste "gesto" de catalogação que reside toda uma nova possibilidade criativa, diria até performativa, a partir do qual, no campo artístico, não só se descobre novos modus operandis no lugar do arquivo, como também se faz validar a partir deste, como obra de arte. Deste modo, a arte contemporânea apropria-se do arquivo e do documento enquanto conceitos, para repensar a sua prática; implicado neste modo de fazer híbrido está um novo paradigma no domínio da estética e do pensamento contemporâneo, originando obras abertas e mais permeáveis à inclusão do observador (Rocha 2013, 42).

A imagem é então o objeto desejado e primordial para a existência e sentido de vida. O mundo, segundo Gunther Anders, transforma-se em fantasma, desde que nos chega somente em imagens. (Belting 2011, 125). À "realidade" pertence um espaço temporal híbrido e fugaz (Belting 2011, 12) e ao lugar do corpo a temporalidade da ação e a conquista desse tempo presente - ser corpo presente no espaço de atuação da performance e relação com o sujeito (espectador). À distância imposta por esta nova realidade, a da imagem, está implicada numa nova atitude na arte contemporânea - a ação - como objeto para a construção da subjetividade e de reflexão estética, bem como motor de transformação social. Um tempo onde surge o fenómeno do hibridismo e que passarei a enquadrar oportunamente.

\section{Desenvolvimento}

Do tempo da academia (reforço da mão), onde a qualidade da arte pertence à obra dominada pelo sistema tradicional de representação, sendo o referente a realidade como a própria autoridade que rege o discurso da arte, a um formalismo estético de 
anti-mimesis, é com o surgimento da fotografia (séc. $X I X)$, com propostas de vanguarda.

Se nos anos 60 do séc. $X X$ se pode falar de um momento pós-abstracionismo, onde acontece um retorno do figurativo com a Pop-art, mais relevante que o sentido do objeto representado, acontece o fenómeno denominado campo expandido da obra de arte: onde se dá o alargamento do sentido da obra, se diluem as disciplinas e se mesclam meios, num espaço e tempo feitos para o experienciar da obra, onde o outro tem lugar e é ativo na sua fruição. Nessa mesma década, domina o efeito da anti-arte e surge o fenómeno do happening caraterizado por um anti-formalismo assente nas primeiras performances, onde ações se desenrolam segundo estratégias de catharse blasfemas, violentas e perigosas.

Um tempo em que o papel do artista se liberta das convenções racionais e normas sociais estabelecidas, dando lugar a uma prática mais ativa e participativa na sociedade; e cujos modos operativos (da performance), vão implicar a novas formas de expressão autoral - é exemplo o trabalho de Joan Jonas, cujas instalações de vídeo e performances convivem com uma prática de subversão (The Feel of Things, 2004), subjacente à mistura das várias linguagens e de conteúdos, posicionando a relação entre a obra, o artista e o observador num questionamento constante.

Também se pode verificar nas pinturas de Michaël Borremans uma construção da narrativa pictórica que parte de procedimentos técnicos e estratégias de encenação, como proto-performance ${ }^{1}$ (Schechner $2006,125)$ para o procedimento da imagem. De acordo com estes novos modos do fazer, podemos afirmar que a pintura renasce à medida que o crossmedia, e a intermedia avançam, sempre segundo um novo modus operandi: ou seja, a partir de um método antigo para gerar algo novo, com uma nova aparência, um novo media.

Partindo do entendimento da produção plástica moderna e contemporânea, pela inclusão de propriedades performativas (Goldberg, 1979), bem como por um $(R e)$-Encantamento do ser humano numa busca pelo sentido do sagrado; como premissa para a presente investigação de doutoramento em curso, "Corpo Transpessoal: O contributo da performance espiritual para a construção pictórica" e propósito deste artigo; onde se pretende perspetivar a utilização do corpo transpessoal no contexto da performance, no âmbito dos processos de transferência como matéria de questionamento e respetivas implicações ontológicas e processuais. Com especial enfoco na prática da pintura multimodal, onde o vídeo tem um papel preponderante na construção das narrativas das ações entre o corpo e a imagem, pois não só é um médium documental dos registos performativos, como é também objeto artístico independente videoarte - mas que emerge sempre do uso do corpo performativo. O real ritualizado como objeto de vídeo.

Investigação que pretende contribuir para a atividade projetual da prática artística, no contexto do estudo da antropologia da imagem, da performance e da pintura. Colocando-se a seguinte questão como guia para a práxis e poiesis: de que forma a performance (espiritual) contribui para a construção pictórica, bem como os demais fazeres plásticos?

\section{O projeto - "Corpo transpessoal: O contributo da performance espiritual para a construção pictórica"}

Este estudo vai do tradicional sistema de representação, à nova figuração na arte, como um tempo onde surge o fenómeno do hibridismo. E parte da produção plástica moderna e contemporânea integra propriedades performativas tanto na práxis, bem como nos objetos artísticos daí resultantes.

Como já anunciado, é com o surgimento da fotografia (séc. XIX), que se altera toda uma perspetiva na construção da imagem como uma realidade autónoma, dando lugar a um formalismo de anti-mimesis, independente de dinâmicas representacionais e ilusórias.

Implicado na mudança deste paradigma estético está a ascensão da ciência e da tecnologia, com raízes no Iluminismo e explorada pela Revolução Industrial. De tal modo que a realidade moderna regida por um investimento na crença da economia cultural, acentua o desencantamento do mundo (Max Weber, 1910), já iniciado pelo processo da secularização ocidental - com o qual surgiram diferentes movimentos de vanguarda, cuja produção plástica se rege pelo confronto entre os ideais modernistas e as noções metafísicas da obra de arte e do sujeito que a percebe.

Se admitirmos que o encanto é uma forma de conhecimento inerente à consciência humana, é, em si mesmo, um ideal estético; bem como faz parte fundamental do programa desencantador da modernidade e que se estende aos dias de hoje. Colocando-se, desta forma, a importância da arte no domínio do poder político, responsável por um novo paradigma cultural, que envolve um sentido de comunidade, uma perspetiva ecológica, e um acesso a fontes míticas e arquetípicas da vida espiritual (Gablik 1991). 


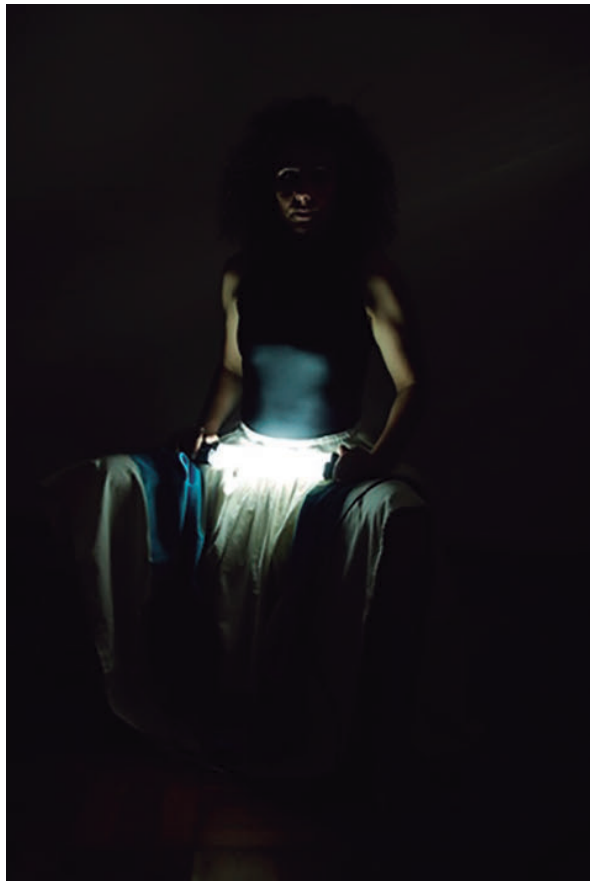

Figura 1 - Partindo do arquétipo do "sagrado feminino": registos fotográficos de ações performativas em estúdio, com vista em realização de vídeos performativos (Fonte: própria).

Vivemos cada vez mais em ambientes violentos, com estilos de vida conflituosos, preenchidos por tensões que turvam a nossa visão interior e nos tornam autómatas; a arte espiritual do nosso tempo é necessária como um lugar de descanso, um ponto fixo, um foco e um modo de nos reconectar com a humanidade e com o universo (Fanning 2018).

Como tal, é necessário a conquista do tempo presente, o aqui e agora (Schopenhauer, 1819), ou seja, ser presente, premissa de atuação para a concretização de uma Performance e tema também explorado por exemplo, por Marina Abramovic, na performance The artist is present, 2010, no MOMA de Nova lorque.

Tomemos então a proposição ser corpo, ser presente como mote para esta pesquisa de natureza interdisciplinar e com um modus operandi "particular"; na medida em que se propõe como método de estudo a observação participativa com base na integração de uma rotina de prática meditativa (yoga, exercícios de respiração e corrida), entendida como proto-performance para o estudo da consciência e de seus estados não ordinários (holotrópicos).

La historia de la performance lleva al extremo esta vinculación entre acción y artista. La utilización de su próprio cuerpo como instrumento de trabajo acentua la dimensión espiritual del arte, un vínculo en el que también insiste Sloterdijk identificando la acción con la práctica continuada y necessária de un ejercicio que tiene algo sempre de iniciático. (Cornago 2017, 145)

Esta prática tem como princípio "acabar com a ilusão do eu", que para além do pessoal se pretende transcender a um nível mental, emocional, corporal e espiritual, o transpessoal; e permite estabelecer uma relação íntima da própria existência, com o fluxo vibratório das várias dimensões subtis do mundo material (as energias telúricas e as energias cósmicas).

Este processo convoca um dos focos de investigação de Schechner dos estudos performativos, o denominado "comportamento" que obrigatoriamente se produz, uma transformação através da própria experiência de um fazer físico e sensível. De acordo com Óscar Cornago (Cornago 2017, 144), podemos resumir três elementos com os quais se constrói a ação como discurso cultural. O primeiro refere-se à urgência da necessidade, do fazer no presente (caraterística própria da ação) e que implica obrigatoriamente um corte com a realidade do momento, uma rutura com o tempo; colocando a história em suspenso - um processo de passagem liminar. Ao segundo momento está comprometido a promessa de transformação, na medida em que à intenção intrínseca à ação está o desejo de que algo deixe de ser como era, uma mudança necessária e urgente. Não obstante, a esta transformação está subjacente o terceiro elemento, e que se relaciona com a experiência física e sensível como lugar da ação - e que começa com o próprio.

"The begining of the spiritual must be this "looking beyond" or looking more deeply within" (Lipsey 1988, 7). A meditação é um processo liminar que atua no sistema cognitivo como contributo para o processo da conquista da imagem interna (visão); o modus operandis que permite uma perceção mais subtil da realidade, como contributo para que se revele uma obra mais autêntica, resultante de uma verdadeira necessidade interior (Kandinsky 2002).

É um lugar de silêncio, um voltar-se para dentro, escutar; é o presenciar da experiência do próprio corpo no espaço físico e sensorial. As perceções que a meditação desperta, sugerem em si, uma rutura com o tempo e espaço real, e resultam em reflexões e sensações puras e sensíveis, mensagens que exploro na minha prática; quer nas performances; quer na escolha da imagem, tanto para o vídeo, como para a pintura - expectante de que a intenção do conjunto de trabalhos daí resultante, componha em si uma dimensão visual e sinestésica capaz de permitir aos espetadores uma dimensão emocional transformadora, e, se possível, inclusive espiritual.

I believe that art is a living entity that changes the world; it is a wellspring and a force field that we can tap and through that experience learn to live in new ways. Art transforms our very way of being. If it elevates our consciousness even momentarily, our reality changes within and new possibilities are revealed. (Fanning 2018, 19) 

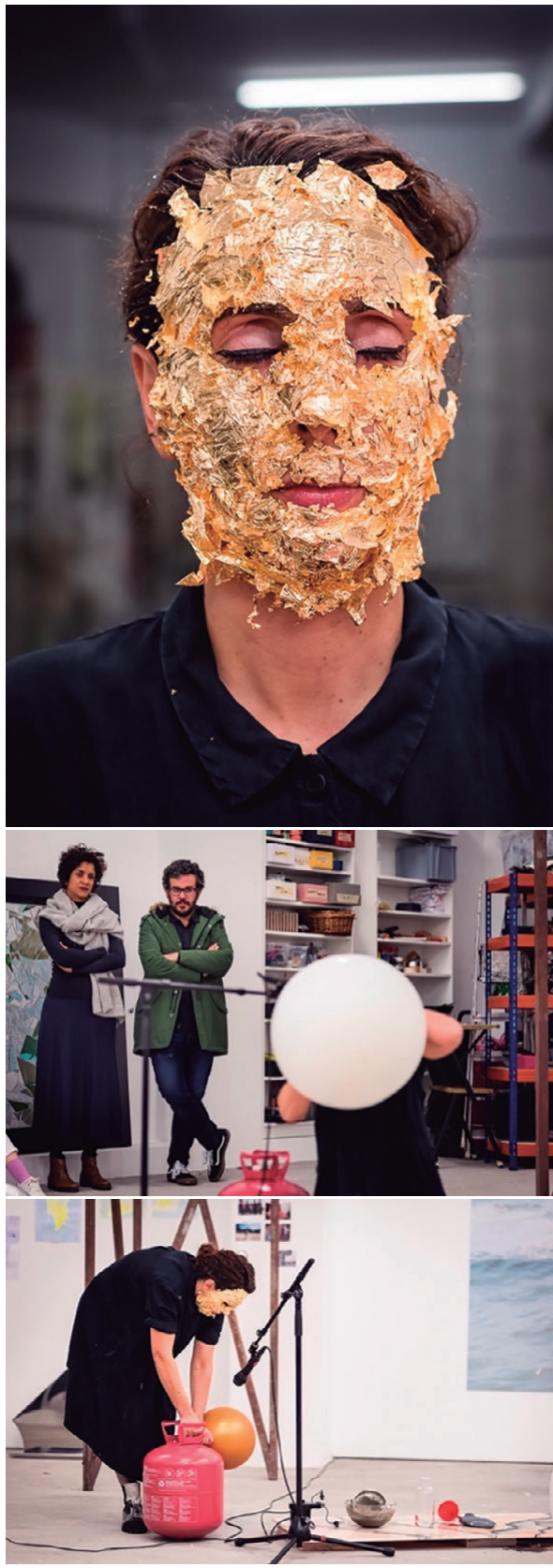

Figuras 2,3 e 4 - "MANIFESTO DO QI", Performance Sonora, no evento VIA ABERTA, Porto, 2018. Comissariado por Luisa Mota, José Maia e José Oliveira. Som manipulado por Pedro Centeno. Créditos fotográficos André Henriques. Fotografia documental da Performance (Fonte: própria). https:// soniacarvalho.com/Manifesto-do-QI
Deste modo, colocam-se as seguintes questões: Qual o contributo da meditação como mecanismo performativo para a escolha da imagem e da perceção do numinoso? E Pintura depois da Performance (espiritual)?

Propõe-se, portanto, uma prática artística mais ativa e participativa na sociedade, onde a experiência estética e ética (do espiritual) se tornam imprescindíveis; desde uma perspetiva holistica do corpo, como ser senciente, cuja práxis se foca nos arquétipos femininos e do estudo da sua figura como lugar de espiritualidade: o real exposto do sagrado feminino como lugar de representação da artista mulher.
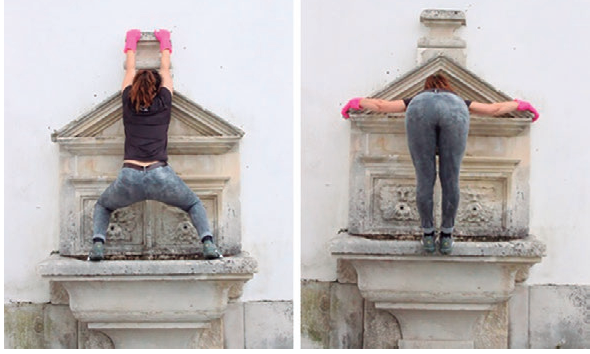

Figuras 5 e 6 - Foto-performance "corpo no espaço e intruso (estranho familiar)", Festival Novas Invasões, Aveiro, 2018 (Fonte: própria).

\section{A metodologia e o corpo de trabalho (invisibilidades)}

Este artigo tem como propósito explorar aqui os processos em investigação artística, revelar etapas tanto práticas como teóricas do projeto e respetivos modos operativos para a construção de narrativas pictóricas; de um projeto que combina diferentes tempos e modalidades no contexto da prática da performance e modos de transferência, tendo em vista a utilização do corpo transpessoal — onde se explora o diálogo entre os objetos plásticos, com especial atenção à pintura.

A componente prática assenta na relação entre o enunciado pictórico e o contexto performativo (real autêntico), para o objeto de represent(ação), ancorada em dois mecanismos criativos, perante os quais os processos picturais emprestam ou perfilham padrões de outros processos, substituindo-os nos seus próprios meios e suportes:

- Narrativas de superfície do performativo (Almeida 2008, Belting 2011): o corpo como meio, ferramenta e suporte, a construção identitária, cultural e o sentido do espiritual, os fenómenos de migração e os rituais de incorporação e interação social.

- Os procedimentos técnicos e estratégias de encenação para o procedimento da imagem e da construção da narrativa pictórica, nomeadamente a participação ativa em workshops (de performance, dança, ritual, etc.). 


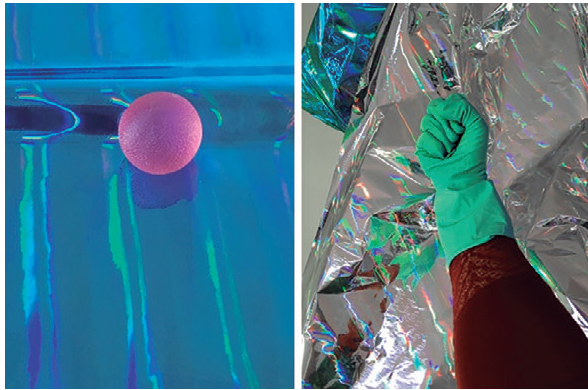

Figuras 7 e 8 - Princípios geradores do projeto: registos fotográficos de ações performatavias em atelier. (Fonte própria)

O objeto de represent(ação) é procedido de uma metodologia regida por diferentes processos técnicos e variadas etapas de execução/manipulação - tais como, proto-performance, performance e aftermath; arquivo de imagens, processos performativos, modos de transferência, pintura, performance, vídeo e instalação -mediados pelo modo operativo nominado play.

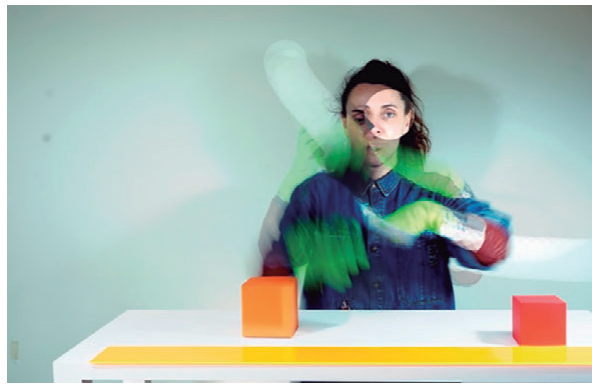

Figura 9 - Princípios geradores do projeto: registos fotográficos de ações performativas em atelier. Imagem manipulada. (Fonte própria)

\section{$P L A Y$}

$\mathrm{Na}$ viragem do século $X X$ para o século $X X I$ houve uma mudança acelerada no modo como o comportamento do jogo ocorreu e o lúdico (play) foi assumindo gradualmente uma dimensão humana, trespassando culturas e produções artísticas. As noções sobre o inconsciente na psicologia, na literatura, em teorias da relatividade na física, e na teoria dos jogos em matemática e economia, são exemplos onde o play passou a ocupar um espaço de problematização. O jogo como construtor da cultura, manifestado nas várias atividades humanas, torna-se uma questão da ordem da antropologia, assumindo dimensões simbólicas, socias e psicológicas.

Dois autores se destacam no estudo do estudo do jogo e do lúdico. Johan Huizinga com "Homo Ludens" (1938), cuja leitura antropológica procura entender a dimensão lúdica como um primado humano, e um elemento fundador das culturas e das civilizações. E Roger Caillois com "Jeux et les Hommes" (1958), cuja vertente mais sociológica procura entender as relações entre o humano e o jogo, em afetação mútua, procurando definir e classificar os jogos. (Dias 2018, 9).

Também nas artes visuais o papel do lúdico - play - reserva em si um espaço de atuação de liberdade, e teve um papel preponderante na perceção da realidade comum e respetiva formalização processual, resultando numa nova perspetiva sobre a mesma: em certos exemplos (como acontece no cubismo, abstracionismo, etc.) ridicularizando, e até mesmo subvertendo uma determinada cultura oficial. Em suma, ao lúdico é reservado um lugar de escape às normas do nosso quotidiano e como tal permite que o sagrado se manifeste no rito; como fundamento espiritual, biológico e necessário ao equilíbrio do ser, este conceito é precioso para o processo criativo que se pretende investigar, nomeadamente na performance e respetivos processos performativos, bem como de transferência e migração de conteúdos, onde o lúdico adquire uma forma própria no espaço de criação do atelier - a verificar estes modos operativos (Figuras 7 -13).

A este modo de fazer, está implicado uma série de episódios que marcaram toda a modernidade estética, já anunciados, como os ready-made de Marcel Duchamp, 1913, nos quais na ação de escolher determinado objeto, se subverte a sua função, tal como acontece, a título de exemplo, no "garrafeiro", ou no "urinol". Entenda-se que no gesto da conceção da obra, ou seja à ação que a procedeu está o potencial estético.
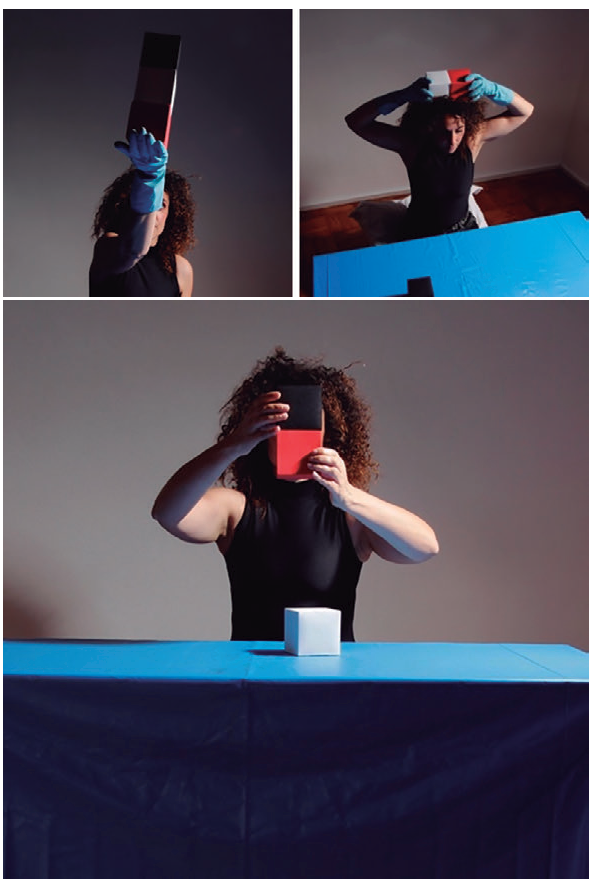


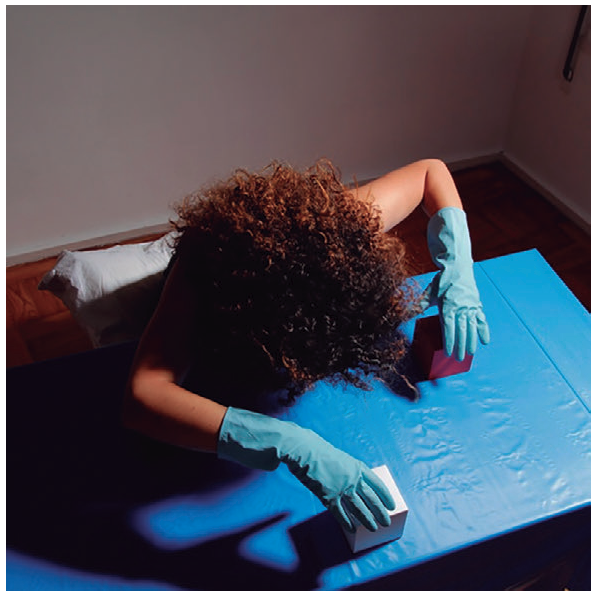

Figuras 10, 11, 12 e 13 - Estudos de ações para a pintura. (Fonte própria).

\section{A ESCOLHA}

Tomemos como pressuposto que no ato de jogar as tomadas de decisão são determinantes no decorrer da ação e contribuem para uma boa performance; como tal, importa aqui analisar o gesto de escolher como um momento em si que integra o sagrado. Marcel Duchamp nas reportagens de George Charbonnier, aquando a sua estadia nos Estados Unidos nos anos 60 , que a ideia da escolha, acoplada ao princípio do fazer na obra de arte, deve de ser entendida como uma questão existencial e metafísica e relaciona-se com os ready-made e todo o seu pensamento.

Recorde-se que já na obra Diálogos Platónicos se questiona o sentido da Arte e da criação artística (poética), no sentido de se tentar perceber se seriam da ordem da perícia ou da ciência. Na Alegoria da Linha, Platão refere que a criação é como um ato de inspiração, é uma atividade não racionalizada, sem regras, assim como não é uma mestria propriamente dita, nem pertence à ciência. $A$ arte aceitável deve de ser submetida (Alain 2002). Tanto no Banquete como no lón o mistério da criação é aquilo que faz vir da não existência para a existência — é neste gesto metafísico da escolha que sobressai nas ações performativas o processo criativo, e faz surgir aquilo que não existia.

As pinturas "Readymade Choices", 2018-2020, partem do "mesmo" gesto onde se procura fazer escolhas, bem como sugere o próprio título é uma alusão aos ready-made e respetivas implicações concetuais; desde logo a escolha da imagem para a pintura - que deriva de uma sessão fotográfica em estúdio com o propósito de registar ações performativas a partir da manipulação de cubos de papel sobre uma mesa e na captação dessa mesma dinâmica tendo em vista um jogo de composição escultórico e abstrato.
O cubo, símbolo feminino, mas também de uma concentricidade plural, aparece-nos aqui como um paradigma das escolhas da mulher, podendo aquela mesa ser a secretária de uma executiva ou a base de ação numa cozinha. Na evolução da cor, a personagem parece levitar, afastar-se do real superlativo. (Pereira 2019, 6)
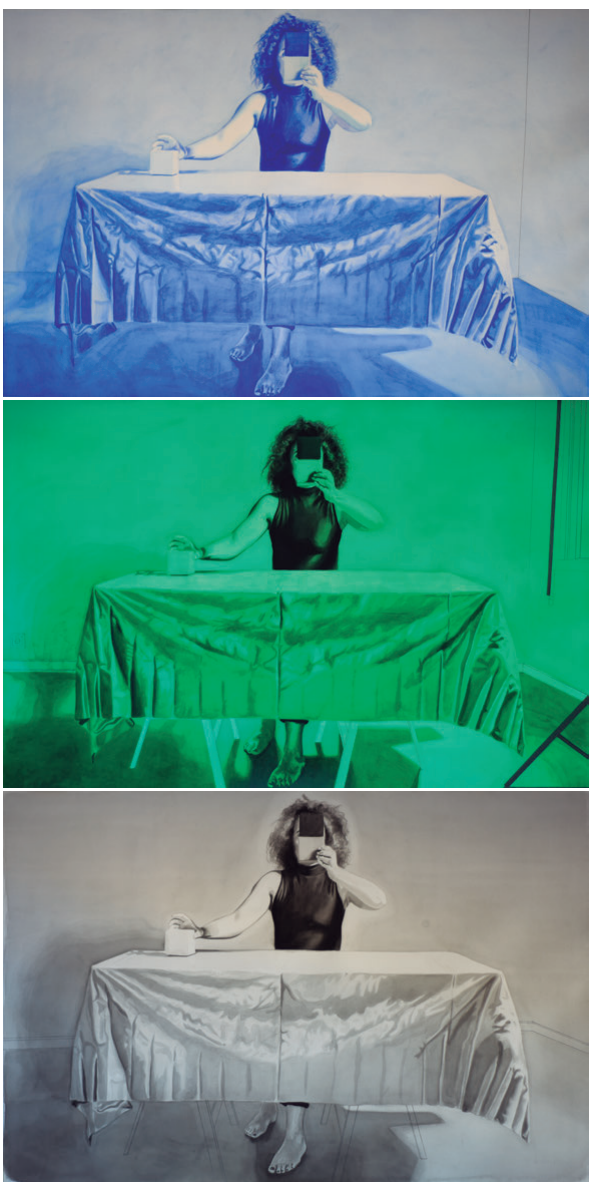

Figuras 14, 15, e 16: Quadríptico: "Readymade choices", 2018 - 2019, aguarela sobre papel, 106 x $154 \mathrm{~cm}$ (cada) (Fonte: própria). A pintura vermelha está em finalização.

E resulta na repetição da mesma imagem quatro vezes, que apesar de idênticas na sua composição, os elementos que as constituem estão representados de maneiras diferentes, realidades paralelas feitas de escolhas técnicas que determinam diferentes ambientes, tempos, estados e leituras dessa "mesma" imagem. A escolha de uma paleta RGB (sistema de cores aditivo, tendo como finalidade a reprodução em dispositivos eletrónicos, tais como monitores de televisão, computadores, scanners e câmaras digitais, etc) deve-se ao fato de que estas cores no sistema 
digital aquando projetadas na sua intensidade máxima resultam no branco, entendido aqui por uma alusão à luz e ao princípio de algo; como estandarte da era contemporânea depositada na fé na imagem.

\section{A potência da imagem, para além da ação - "Struggle Like A (Wo)Man \#1", 2019²}

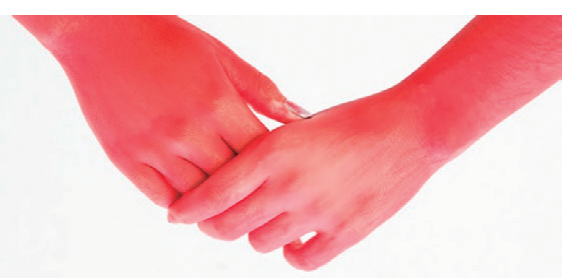

Figura 17: s/ título. Registo fotográfico do workshop Struggle Like A (Wo)Man \#1", 2019.

No âmbito da pesquisa do projeto de tese, aqui em análise, foi realizada a performance pública "Struggle Like A (Wo)Man \#1"3, como resultado de um workshop dirigido à comunidade local, marcou um percurso pela cidade por seis participantes comigo, e foi apresentada no âmbito do Festival Novas Invasões, 2019; tendo sido um dos projetos selecionados ao abrigo do programa de estímulo à criação promovido pela Câmara Municipal de Torres Vedras. Onde lugares como fontes, fontanários e lavadouros e as lides domésticas tornam-se espaços de meditação e de contemplação do $E u$, e diferentes gerações locais se juntam para incorporar o estereótipo do feminino como um lugar de força num campo de batalha multidimensional.

Do workshop, como aftermath resultaram intervenções fotográficas ${ }^{4}$ pelo centro histórico de Torres Vedras.

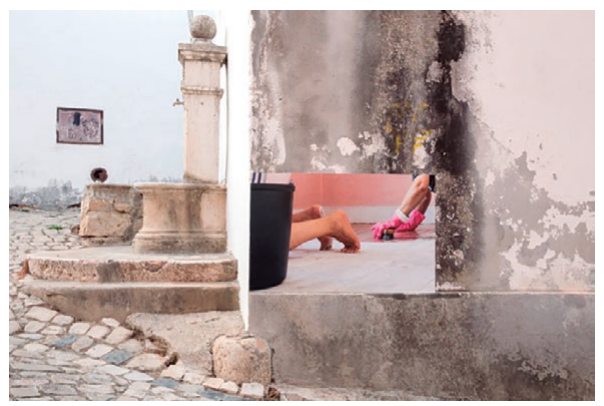

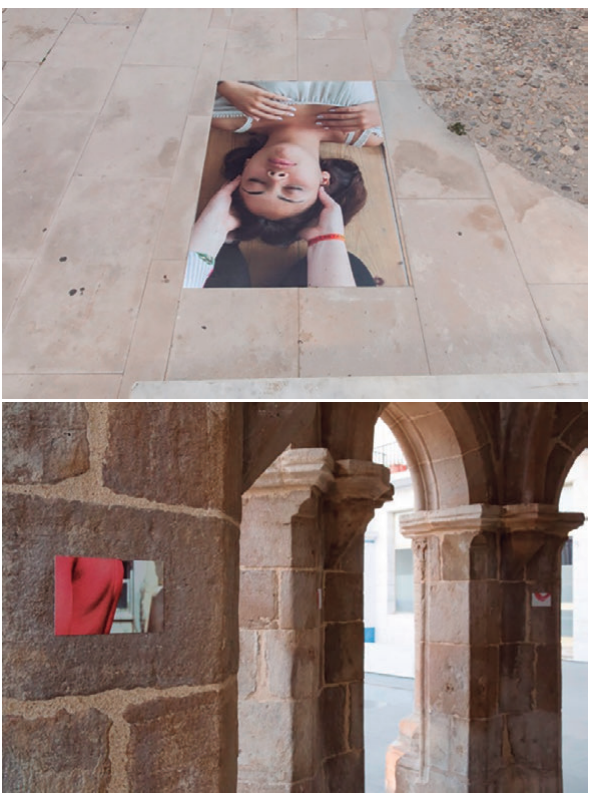

Figura 18-20: s/ título. Registo fotográfico da instalação fotográfica, Struggle Like A (Wo)Man \#1", 2019.

Este projeto insere-se no domínio interdisciplinar da prática performativa ritualística e do uso do corpo com os objetos do quotidiano e do espaço arquitetónico, a partir do fenómeno da "inquietante estranheza" (Das Unheimlich - Freud, 1919) como um estado de desconforto onde algo familiar se torna desconhecido, gerando um sentido próprio onde se mesclam os limites entre o "doméstico-publico e privado", o "social e o sexual" e o "simbólico-sagrado"; e na exploração do registo fotográfico e videográfico, onde se irá seguidamente analisar e contextualizar como os vários arquivos de imagens corporais são criados/produzidos para outros fins para além do documento.

Em jeito de contextualização, do confronto entre documento e acontecimento, a performance assume-se como uma metalinguagem; onde conceitos como performance, performativo, performatividade, passam a ter uma voz cada vez mais forte na teorização das práticas artísticas e sociais da contemporaneidade, abrindo espaço para o entendimento desta disciplina como um campo cada vez mais amplo e flexível e em constante debate.

A confirmar a consolidação da performance nos últimos 50 anos com os Performance Studies, desde Roselee Goldberg, Richard Schchner, Diana Taylor, Rebecca Schneider, entre tantos outros investigadores; onde podemos verificar a validação da Performance art com referências de artistas como Chris Burden, Gina Pape, Ana Mendieta, Stelarck, Marina Abramovic, Berna Reale; Tony Seghal, etc.

A performance é em si um conceito bastante amplo, mas de uma forma muito sucinta entenda-se por 
performance (de arte, de rituais, do cotidiano, play) desde o ponto de vista de Richard Scechener, como "comportamentos restaurados" (Schechner 2006), sugeridos por atos de transferência, onde o corpo e a sua presença é ainda a referência, através das caraterísticas físicas e na presença de um público, tendo em vista a passagem de conhecimentos, tais como, social, memória e um sentido de identidade. Para além destes, temos os atos gerados a partir de uma pós-produção, esteticamente cuidada, no uso de uma prática multimédia; como o vídeo, a fotografia, entre outros; abrindo-se toda uma possibilidade criativa a posteriori da obra através de uma montagem/ criação de vestígios.

$\mathrm{O}$ estatuto dos objetos e das imagens que resultam depois de uma ação, ou seja, o caráter imaterial da arte (Lippard 2001), remonta aos anos setenta e pressupõe uma validação por parte das várias instituições artísticas, que necessitam de objetualizar a experiência, dar corpo a essa ausência; passando a documentar tanto as performances, as ações, bem como os happenings, pelos vários media (intermédia), tais como, fotografia, vídeo, desenhos, texto, entre outros.

Nas décadas de 1960 e 1970, a exploração do potencial do corpo e seus processos orgânicos, passa a ter um papel central para o artista, com o qual, Happenings e ações Fluxus exploram situações do quotidiano e da vida comum, em constante questionamento e confronto com o espetador. No entanto, a dinâmica do corpo e da ação estava limitada pelo próprio gesto, que só existia enquanto acontecimento no aqui e agora; todos os documentos que daí resultavam, tais como fotografias, vídeos e outros documentos eram apenas registos incompletos, relíquias como resíduos de um trabalho.

Este carácter de documento se podría trasladar a otras manifestaciones artísticas. Sin duda, en los años noventa, el tema de la identidade fue um asunto que preocupo mucho a buena parte de los artistas más activos del momento. Una identidade cambiante, no estática, que reivindicaba los márgenes y aquellas formas ocultadas del yo. El feminismo, sin duda, abrió la puerta que otros también traspasaron: minorias sociales y opciones sexuales, principalmente. El vídeo, sobre todo a partir de las primeras manifestaciones del body art, fue un buen medio para reflexionar sobre la identidade. (Álvarez-Reyes 2003, 75)

Tomemos como exemplo os rituais de auto-flagelação de Gina Pane, como potenciadoras do corpo para a compreensão das relações de interdependência entre imagem e ação. Pane, expõe de uma forma brutal a carne e o sangue, a partir de sensações como dor e perigo, como matérias de questionamento, para revelar as fragilidades do corpo humano e da condição feminina.

Em "Anzione Sentimentale", 1971, a artista faz incisões precisas na pele desenhadas por uma lâmina e por espinhos; em “L'Escalade non anesthésiée”, 1971, Pane sobe uma estrutura metálica com degraus com protuberâncias afiadas, de modo que, com o peso dos pés descalços e das mãos apoiadas, perfuravam a pele até sangrar.

A artista desenvolve estudos pormenorizados dos enquadramentos das ações, para que os registos fotográficos e videográficos resultassem não só como documento, mas sobretudo como obra per si imagens psíquicas para além experiência do corpo. Gina Pane, ao prolongar desta forma a ativação da performance, no tempo e na experiência do espetador, está a posicionar a performance para além do efémero; como tal, a fotografia e o vídeo, tornam-se deste modo em objetos performativos de experiência estética, protagonizada pelo ritual.

A literalidade do corpo, a temporalidade da ação, e o papel subversivo da imagem (mais concretamente a partir da noção de repetição e de transferência), situam o objeto no lugar da obra de arte; a partir do qual se dá a consolidação da performance pelos sistemas de arte, para além dos mecanismos comerciais e institucionais.

Seguem-se inúmeros exemplos desta prática, onde o poder da imagem é o lugar da ação: "Leap Into The Void", de Yves Klein, 1960; "Dance or Exercise on the Perimeter of a Square (Square Dance)" de Bruce Nauman, 1968; "Atirar", 1971, e "Trans-Fixed", 1974, de Chris Burden; "Untitled (Glass on Body Imprints), Ana Medieta, 1972; "Variations on Discord and Divisions", Mona Hatoum, 1984, etc

A partir destes modos operativos desenvolvem-se diferentes perspetivas sobre a performance aliadas às novas tecnologias, a salientar os audiovisuais para gerar novas obras - intermedia; derivados de conceitos como processos performativos, performatividade, ação, happening, re-enactment, etc., como conceitos que vieram ampliar a natureza discursiva deste género.

En cambio, lo Intermedia, idea flotante entre la poesia, la acción y el lenguage de los media em su dimensión visual y/o sonora, supone la reclamación de um posicionamento consciente (...) en el legado posterior a la Segunda Guerra Mundial, donde lo experiencial, procesual y corporal irrumpen, incluso desde su ausência, como la herramienta para articular afectos o teorias sobre el sujeto, el tiempo, el espácio y la materialidade. Un posicionamiento ideológico y especulatico que, a su vez, asumió al ready-made duchumpiano, antecedente necessário para la ruptura de idea de arte en tanto objeto centrado em lo retiniano y anclado en modernidade más hermética. (Hinojosa 2017, 26)

\section{"Struggle Like A (Wo)Man \#1", 2019 . SINOPSE}

Fontes, fontanários, lavadouros como lugares de encontro com a comunidade, espaços públicos - não só de abastecimento de água, como também serviram e ainda servem para as lides domésticas, onde mulheres se reuniam para lavar as roupas, por a conversa em dia e soltar a voz em cantares à desgarrada. São também lugares de meditação e contemplação, cuja água e suas propriedades de espelho dão lugar ao 
confronto com elas próprias como forma de estudar os limites do corpo performático e das suas angústias interiores, questões e estranhamento - ou até mesmo terror - do seu Eu.

A performance desenvolve-se a partir de um diálogo entre a fonte, o elemento da água e os corpos: cuja partitura se compõe com origem descontextualização do gesto das lides domésticas, e de um jogo formal entre as escovas de chão, e o órgão genital feminino, bem como a ação de esfregar e o movimento erótico, em comunhão com a experiência do sagrado manifestada nos rituais do quotidiano - enquadrado pelo cântico tradicional "Oliveirinha da Serra" .

É a partir desses distantes universos que desenvolveram os gestos a partir das situações como as atividades de limpeza e higiene que uma casa exige, para a construção de uma narrativa performativa; como uma reflexão sobre a condição da mulher como um lugar de força num campo de batalha multidimensional, numa sociedade patriarcal que é a nossa e em comunhão com a experiência do sagrado manifestada.

A marcha inicia a performance, marcando um percurso pelo centro histórico da cidade de Torres Vedras, até à fonte de S. Miguel, no jardim do Choupal. Numa coreografia desenhada pela manipulação de objetos de um quotidiano longínquo; tais como escovas de esfregar o chão, socas, bacias da roupa das lavadeiras, e cujos ritmos repetitivos induzem a estados de hipnose e permitem uma relação história e corpórea da passagem do tempo simbólico; bem como desenrolam memórias arquetípicas do lugar de representação do feminino.

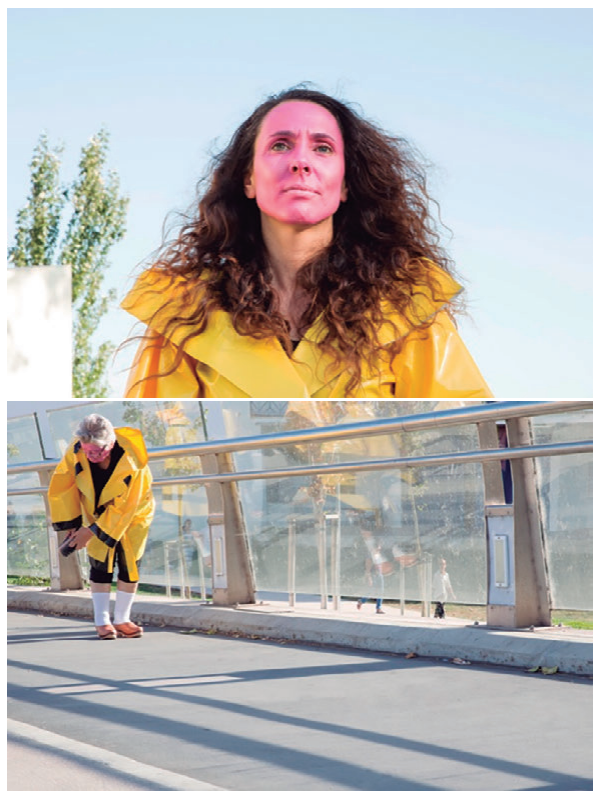

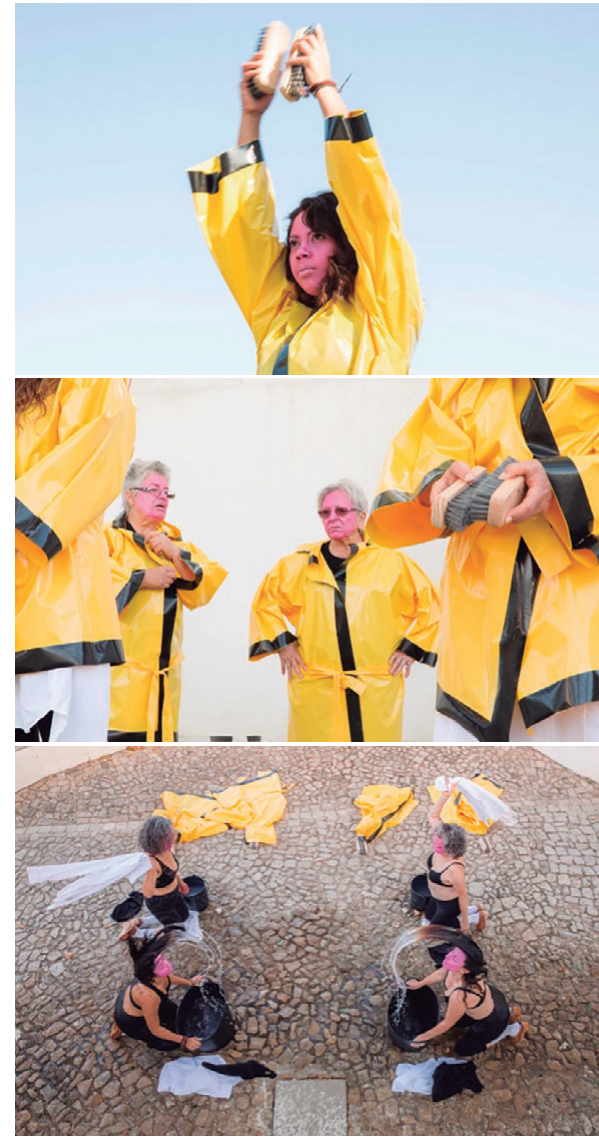

Figuras 21-25: "Struggle Like A (Wo)Man \#1", 2019. Registo fotográfico da Performance.

\section{WORKSHOP}

O workshop teórico e prático foi dirigido à comunidade feminina local Torriense, e compreendeu um grupo de várias gerações, dos 15 anos aos 78 anos; tendo sido realizada em quatro dias.

Desenvolveu-se a partir de exercícios performativos de autoconsciência das perceções de comportamentos estereotipados relacionados à condição feminina; nomeadamente gestos do quotidiano a serviço da limpeza e nessas ações repetitivas explorar em si uma dimensão espiritual e, assim, incitar o inconsciente com rituais de transformação.

Com o propósito de desafiar a estrutura psicológica e emocional, bem como os limites físicos e mentais do corpo, forçando-o a reviver condutas estereotipadas da figura da mulher e do doméstico, para através de processos performativos e de exercícios de grupo dessacralizar os mesmos. Nomeadamente, através de gestos repetitivos e o uso consciente da respiração, desenvolveram-se estados meditativos 
de introspeção, de forma despertar memórias arquetípicas e compreender a história de um corpo (feminino) coletivo; que serviram de coordenadas para a composição do movimento da narrativa performativa.

Foram realizados exercícios de longa duração tendo em vista o desenvolvimento da capacidade de concentração e de resistência, necessários à concretização da performance coletiva. No decorrer do workshop foram sendo feitas conversas sobre o estado da Performance art.

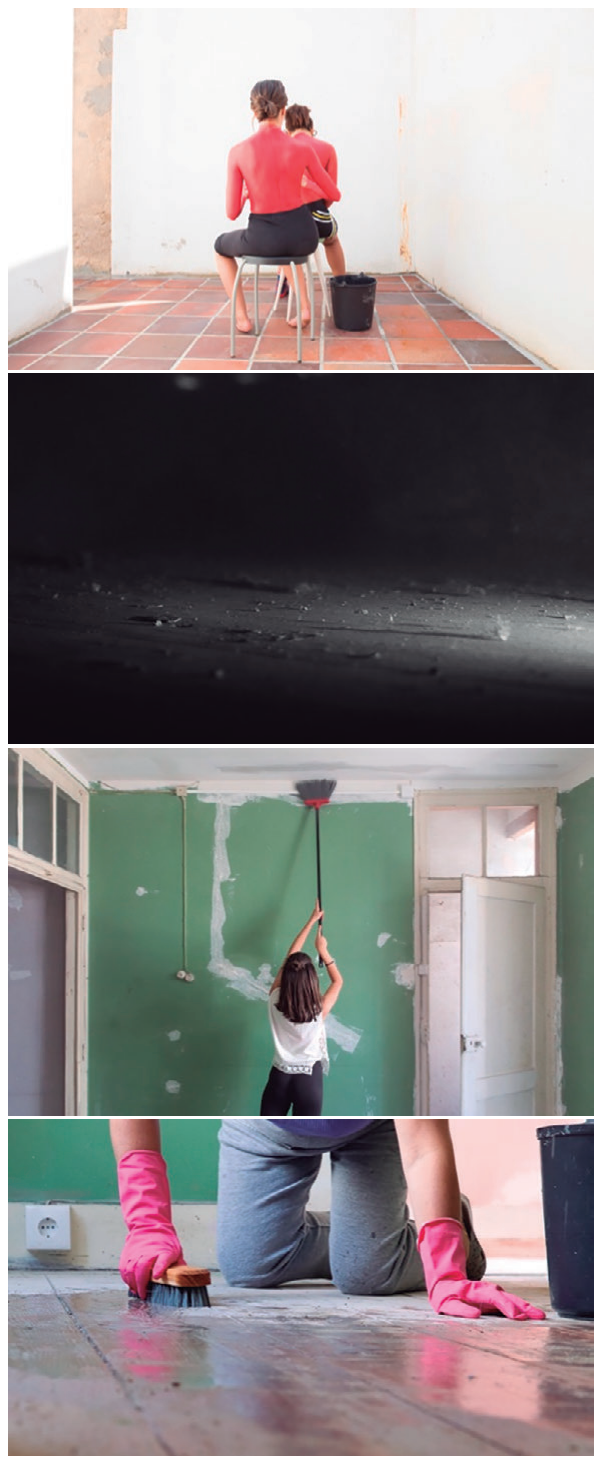

Figuras 26-29: Registo fotográfico do workshop "Struggle Like A (Wo)Man \#1", 2019.

\section{VÍDEO-PERFORMANCE: "Fricção Temporal"}

Os vários arquivos de imagens corporais que procederam do workshop foram criados/produzidos para outros fins, para além da documentação; tais como, obra fotográfica para a instalação no espaço público, e vídeo-performance.

"Fricção (In) Temporal" (vídeo-performance) resultou em reflexões corporais sentidas durante o workshop, como novas formas de registo a partir do legado da linguagem do cinema e do vídeo. O vídeo, mais que outras linguagens, descreve a condição psicológica do que física (Krauss 1976, 50-64), prolongando no espetador a experiência da ação no espaço e no tempo.

Propõe-se um diálogo entre dois momento da ação e temporalidade distintos; sendo que um vídeo apresenta um corpo feminino pintado de cor de rosa e enquadrado por um plano de detalhe da zona púbica, onde é ativado pela descontextualização do gesto de esfregar - semelhante ao das lides domésticas ou de caráter sexual, tais como as atividades de limpeza e higiene que uma casa e um corpo exige - e de um jogo formal entre as escovas de chão, e o órgão genital feminino entra num diálogo de ambivalência.

Da ação de esfregar ao movimento erótico, resulta um sentido de comunhão com a experiência do sagrado feminino manifestada nos rituais do quotidiano. O som que resulta do gesto de esfregar as escovas de palha de aço provoca um estado de tensão ou até mesmo de estranheza que interessa aqui provocar e explorar perante a imagem sedutora. Abordando assim o fenómeno da "inquietante estranheza" (Das Unheimlich — Freud, 1919) como um estado de desconforto onde algo familiar se torna desconhecido, gerando um sentido próprio onde se mesclam os limites entre o "doméstico-publico e privado", o "social e o sexual" e o "simbólico-sagrado" e permite uma reflexão sobre a condição da mulher como um lugar de força e de esforço num campo multidimensional.

Assim sendo, esta ação é acompanhada pelo vídeo do desenrolar da rodilha, o desenrolar de um tempo ancestral por umas mãos de uma mulher anciã, que no gesto repetitivo induz a um estado de hipnose e permite uma relação história e corpórea da passagem do tempo simbólico onde não se descreve um lugar, permitindo assim uma meditação, abstração da tarefa que se desenvolve como um loop, ciclo hipnótico no seu conjunto. 


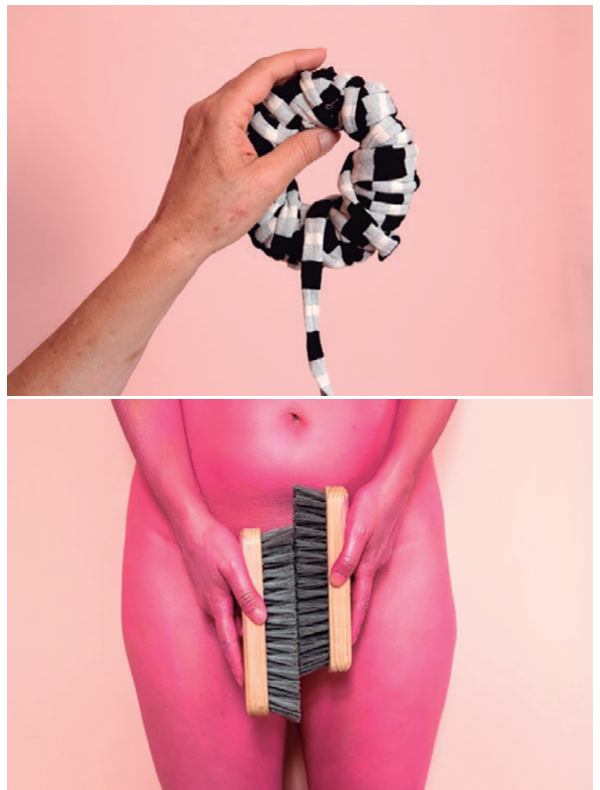

Figuras 30,31: vídeo-still do vídeo-performance "Fricção (IN) Temporal", 2020.

Ao validar o registo, seja em vídeo-performance ou foto-performance, como obra performativa, aparentemente estamos a anular uma das premissas fundamentais da performance até então - o caráter imaterial e efémero da obra como posicionamento imprescindível até então, tanto para a sua existência, como também como elemento de resistência política perante a sua comercialização - no entanto como refere Schneider:

Una vez la acción ha sucedido, penetra en el campo mnemotécnico de la matéria y, por tanto, no solo puede ser reproducida sino que permanece, en sí misma, dentro del espácio de la memoria"5. (Schneider 2010, 176)

À vídeo-performance pertence a capacidade de fixar no tempo uma memória corporal, eternizar um presente, bem como, a recriação/manipulação dessa mesma realidade que o próprio meio permite, gerando novos sentidos a partir da especificidade da linguagem e da temática da obra. Nestas condições, ao separarmos o corpo físico do artista, do seu processo natural, como acontecia na body art, estamos a posicionar a vídeo-performance como uma categoria artística. Assumindo-se como dispositivo para a visibilidade da obra e a partir de uma linguagem própria, instaura o ritual - atuando como dispositivo holista no espetador no aqui e agora - uma experiência estética e ética (do espiritual).

\section{Considerações finais}

A pesquisa do corpo transpessoal é aqui entendida como resgate de uma memória ancestral transcendente, de uma natureza instintiva feminina e seus arquétipos, impregnada e impregnante de cultura - a partir da experiência do corpo performativo, do Rito e do sentido de comunidade (para além do pessoal).

Dos objetos plásticos resultantes - performances, vídeo-performance, foto-performance, pinturas, etc, que se entrelaçam e se ativam uns aos outros; atuam como dispositivos para a experiência do numinoso e propõe uma experiência direta, individual como forma de transcendência e revelação.

A transferência de sistemas de códigos que ocorre na conceção deste projeto e na sua dimensão performativa, implica sempre a colocação do espetador numa determinada situação percetiva, gerada a partir do real - do "corpo presente" e da escolha da potência da imagem.

Porquê o retorno à pintura, depois de todos os processos performativos? A construção pictórica só acontece depois da Performance. E resulta sempre de uma verdadeira necessidade interior da experiência corporal, de uma ação viva - performativa e antropológica - para a construção de uma imagem. É a represent(ação) da poética da ação.

Portanto uma pintura consiste numa reflexão sobre a experiência do corpo transpessoal, sensitivo, intuitivo, como sendo uma pausa in foco no espaço-tempo. À contemplação acoplada ao ato de fazer, circunscreve em si a revelação de algo oculto, algo que transcende a própria realidade e se torna sagrado - é o silenciar de pensamentos para que aconteça a mais sábia resposta, na compreensão clara de uma "visão".

Pintura enquanto performance - na pintura encontra-se no ato de fazer um pressuposto próprio da meditação e do sentido do espiritual; ou seja, pintar é voltar-se para dentro, no espaço seguro do atelier, é o desligar do mundo exterior, silenciar. Um lugar da não ação, para abrir espaço à simples contemplação transformadora.

Nota: agradeço aos meus orientadores Rui Serra e co-orientadores João Peneda e Paulo Bernardino Bastos, pelo contributo constante e dedicado a este projeto.

Este trabalho é financiado por fundos nacionais através da FCT - Fundação para a Ciência e a Tecnologia, I.P., no âmbito do projeto UIDB/04057/2020.

Este projeto é financiado por fundos nacionais através da FCT - Fundação para a Ciência e a Tecnologia, I.P., no âmbito do projeto UIDB/04042/2020.

\section{Notas Finais}

\footnotetext{
${ }^{1}$ Schechner define o processo performativo como uma sequência no espaço e no tempo, que se subdivide em três etapas: proto-performance, performance e aftermath.

2 "Struggle Like A (Wo)Man \#1", 2019, Festival Novas
} 
Invasões, Torres Vedras, Portugal. Tempo 50'. Artista Sónia Carvalho; Curadoria Jorge Reis; Gestão do projeto Daniela Ambrósio; Fotografia Marisa Bernardes; Figurinos Guita Gonçalves; Produção EMERGE; Parceiros Associação Incluir+ e Câmara Municipal de Torres Vedras, 2019.

${ }^{3} \mathrm{https}$ ://soniacarvalho.com/Struggle-Like-A-Wo-Man-1

${ }^{4}$ https://soniacarvalho.com/INSTALACAO-SLAWM-1

5 SCHNEIDER, Rebecca, "Los restos de lo escénico (reelaboración)", em Isabel de Naverán (ed.), Hacer historia, reflexiones desde la pratica de la danza, Universidad de Alcalá, Mercat de les Flors, Barcelona, 2010, pág.176., in LLÁMALO PERFORMANCE! HISTORIA, DISCIPLINA Y RECEPCIÓN"; Juan Albarrán, Iñaki Estella (Eds), Publicações Brumaria A.C., Madrid, 4. ${ }^{\text {a }}$ edição, 2017, p.35.

\section{Bibliografia}

Álvarez-Reyes, Juan Antonio. 2003. No todo es documental. apud Monocanal, Madrid, Museo Reina Sofía in "LLÁMALO PERFORMANCE! HISTORIA, DISCIPLINA Y RECEPCIÓN", Vol. 4. ${ }^{a}$ edição. Madrid: Brumaria.

Alain, Badiou. 2002. Pequeno manual da inestética. Traduzido por Marina Appunzeller. São Paulo: Estação Liberdade.

Almeida, Paulo Luís Ferreira. 2008. La dimensión performativa de la práctica pictórica: análisis de los mecanismos de transferencia de uso entre distintos campos performativos. País Vasco: Facultad de Belllas Artes de La Universidad del País Vasco, (tese de doutoramento, texto policopiado).

Belting, Hans. 2011. A verdadeira imagem. Entre a fé e a suspeita das imagens: cenários históricos. Porto: Dafne.

Cornago, Óscar. 2017. Sobre el mito de la acción y las acciones mínimas. in "LLÁMALO PERFORMANCE! HISTORIA, DISCIPLINA Y RECEPCIÓN", Vol. 4. ${ }^{a}$ edição. Madrid: Brumaria.

Dias, Fernado Rosa. 2018. ARS LUDENS - ARTE, JOGO E LÚDICO. in CONVOCARTE - REVISTA DE CIÊNCIAS DA ARTE N. ${ }^{\circ} 6$ | SET'18 Lisboa: FBAUL CIEBA.

Fanning, Leesa K. 2018. Encountering the Spiritual in Contemporary Art. New Haven: Yale University Press.

Gablik, Suzi. 1991. The Reenchantment of Art. Nova Iorque: Thames and Hudson.

Hinojosa, Lola. 2017. Objetualizar la experiencia, historiar la ausencia. Notas sobre performance y museos. in "LLÁMALO PERFORMANCE! HISTORIA, DISCIPLINA

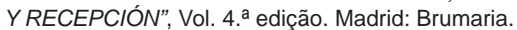

Kandinsky, Wassily. 2002. Do espiritual na Arte. Vol. 5. ${ }^{\text {a }}$ edição. Lisboa: Dom Quixote.

Krauss, Rosalind. 1976. Vídeo: The Aesthetics of Narcissism. Nova lorque: The MIT Press.

Lippard, Lucy. 2001. Six Years: The Dematerialization of the Art Object from 1966 to 1972. Berkeley / Los Angeles: University of California Press.

Lipsey, Roger. 1988. The Spiritual In Twentieh-Century Art. Nova lorque: Dover.

Pereira, Helena. 2019. NOVAS BABILÓNIAS. Braga (catálogo de exposição coletiva).

Rocha, Miguel. 2013. A obra no gerúndio. Lisboa: Faculdade de Belas Artes da Universidade de Lisboa, (tese de doutoramento, texto policopiado).

Schechner, Richard. 2006. Performance Studies, An Intriduction. Nova Iorque: Routledge/Taylor \& Francis Group.

Schneider, Rebecca. 2010. Los restos de lo escénico (reelaboración). Barcelona: Mercat de les Flors. 